\title{
PREFERENCES FOR VIRTUAL MUSIC THERAPY AND THE USE OF TECHNOLOGY IN THE PRACTICE OF CZECH MUSIC THERAPISTS - A DESCRIPTIVE CROSS-SECTIONAL STUDY
}

\author{
Jan Koucun ${ }^{1}$, Jiri Kantor ${ }^{2}$ \\ 1,2 Palacky University Olomouc, Czech Republic
}

\begin{abstract}
The preventive restrictions imposed at the beginning of March 2020 led to the interruption of the therapeutic practice of most music therapists in the Czech Republic. The aim of this descriptive cross-sectional study was to find out what impact this situation had on the music therapy community at the end of May 2020, how many music therapists gained experience with virtual music therapy (VMT) and how ICT and other technologies were used in music therapy practice. A survey with an extended version of a questionnaire created by Gilboa, Weiss and Dassa (not yet published) for the purpose of an international survey in music therapy was used for data collection. Based on the findings, most music therapists at the time had no experience with VMT, but a small number of practitioners were interested in using VMT even after the end of the lockdown. ICT has been used more for receptive music therapy activities and its wider application faces problems such as a lack of knowledge and skills in the use of ICT in the context of music therapy. Based on these findings, a project focused on the implementation of best-evidence concerning VMT into Czech music therapy practice was launched. Also, we recommend creating projects focused on the use of ICT (including applications in music therapy conducted faceto-face) in the near future.
\end{abstract}

Keywords: Music therapy, virtual, telehealth, pandemic, survey, ICT, COVID.

To cite this article:

Koucun, J. \& Kantor, J. (2021). Preferences for Virtual Music Therapy and the Use of Technology in the Practice of Czech Music Therapists - a Descriptive Cross-Sectional Study. Education. Innovation. Diversity, 2(3), 14-21. DOI: https://doi.org/10.17770/eid2021.2.6708

\section{Introduction}

The onset of the pandemic in spring 2020 in the Czech Republic resulted in long-term epidemiological restrictions, as well as serious challenges, for most professions. One of the professions strongly influenced by the repeated lockdowns were arts therapists. In the course of 2020-21, many arts therapists in the Czech Republic had to suspend their therapeutic practice for a long time or start working through telehealth. However, the transfer of therapeutic practice into the virtual space is, in the case of arts therapies, much more difficult as compared with verbal therapy. As far as telehealth is concerned, the greatest complications were experienced by music therapists as all publicly available online communication platforms are primarily intended for verbal communication. Music therapy is particularly complicated by the inability to synchronize sound and by the deformation of sound quality when playing an instrument or singing.

Therefore, virtual music therapy (VMT) had been used only sporadically before the pandemic, which is also confirmed by the limited number of publications. Vaudreuil et al. (2020) investigated the use of VMT among military-connected populations on a continuum of clinical and community engagement and found positive responses, including a decrease in pain, anxiety, and depression. According to a case study conducted by Lightstone, Bailey, \& Voros (2015), VMT was effective in the treatment of a patient with post-traumatic stress syndrome and depression. Fuller \& McLeod (2019) described several models of VMT used for families of children with hearing impairment. More scientific evidence about VMT was published after 
the beginning of the pandemic. We conducted a scoping review and found 10 articles published from the onset of the pandemic to the $25^{\text {th }}$ October 2020 (Kantorová et al., 2021). Moreover, we described different adaptations to music therapy practice, including adaptations to the goals, methods/techniques, space, musical instruments, technologies, flexibility and logistics, etc.

A growing number of publications suggest that during the pandemic, music therapists became interested in VMT due to the adverse effects of the preventive measures on traditional music therapy practice (Gaddy et al., 2020). Regarding the fact that there are many music therapists in the Czech Republic outside the clinical sphere (Kantor et al., 2016), an increased interest in VMT as an alternative to face-to-face music therapy was expected. During the lockdowns, music therapy, just as all external services, was immediately suspended in many workplaces. The most serious restrictions affected social services, which are the most common working environments for music therapists. A question emerged at the beginning of the pandemic as to how music therapists could be assisted in adapting their practice to the virtual environment. It was important to identify how many music therapists were experienced in VMT and how many music therapists considered the use of VMT in their practice. It was also necessary to identify the extent to which music therapists used ICT in their music therapy practice, what obstacles they faced and what could help them utilise these resources. The application of VMT is largely dependent on the ability to use ICT. Therefore, data was needed to inform further planning of effective interventions to support music therapists during the pandemic. Regarding the fact that during this time, an international cross-sectional study was being performed in the Czech and Slovak music therapy community led by Avi Gilboa, Ayelet Dassa and Chava Weiss aimed at evidence-based description of the music therapy profession, we added in the domestic version of the questionnaire items focused on the current situation regarding the use of VMT and ICT in the music therapy process. This paper analyses only the data acquired from these additional questions in the Czech Republic and Slovakia, since the findings may be of high importance in the ongoing pandemic time.

\section{Methodology and sample}

We used the descriptive cross-sectional study design with a questionnaire survey. The study was approved by the Ethical Committee of Bar-Ilan University (E.MUS.2021-13). The goal of the study was to answer the following questions:

- Did music therapists start to use VMT as a result of the pandemic and do they consider the use of VMT after the pandemic?

- For what purposes do music therapists use ICT?

- What barriers do music therapists face in the use of ICT in their practice?

We used a modified version of the questionnaire created by a group led by Avi Gilboa, Ayelet Dassa and Chava Weiss and further modified by the authors of this paper. In this modified version, 5 questions were added (the questionnaire is attached in the Appendix 1). The questionnaire includes general data (including respondents' demographic data), data about their music therapy practice, etc. The additional items used a combination of questions with dichotomous answers, scales and open questions. The data analysis was based on descriptive statistics computed in MS Excel and absolute and relative frequencies.

The survey was conducted in the community of Czech and Slovak music therapists. Both countries share common history and similar language and most Slovak music therapists received training from Czech lecturers. Music therapists in the Czech Republic are organised in the Music Therapy Association of Czech Republic (CZMTA) and several minor associations. The number of registered music therapists in CZMTA is about 200, including non-practicing and senior music therapists and music therapy students. The number of music therapists in Slovakia is not known but we suppose it to be fewer than 40 persons (depending on the 
professional criteria). Currently, there is no functional music therapy association in Slovakia and some Slovak music therapists are registered with CZMTA. Regarding the fact that music therapy lacks statutory recognition in both countries and for music therapists it is not obligatory to register anywhere, the number of respondents in the basic sample can only be estimated.

Inclusion criteria: practicing music therapist (including music therapy students and practitioners who do not achieve the professional standards established by CZMTA), whose practice is conducted in the demographic area of the Czech Republic or Slovakia. Exclusion criteria: respondents who lack qualification consisting of at least long-term training (more than 100 hours) or respondents who do not practice music therapy with clients.

The survey was delivered through CZMTA, Facebook groups/other social media and respondents were kindly requested to forward it to music therapy practitioners not registered with CZMTA. The data was collected during May 2020 and two reminders were sent by the CZMTA office. Eventually, we included 64 respondents from the Czech Republic and 13 respondents from Slovakia, together 77 respondents. No completed questionnaire was excluded from the sample.

The demographic information (including years of experience in music therapy) concerning the research sample is shown in Table 1.

\section{Table 1 Demographic characteristics of respondents}

\begin{tabular}{|c|c|c|c|}
\hline \multirow{3}{*}{ Gender } & & Czech Republic & Slovakia \\
\hline \multirow{3}{*}{ Age } & Female & $51(80 \%)$ & $10(77 \%)$ \\
\cline { 2 - 4 } & Male & $13(20 \%)$ & $3(23 \%)$ \\
\cline { 2 - 4 } & $\leq 30$ & 3 & 0 \\
\cline { 2 - 4 } & $31-40$ & 15 & 5 \\
\cline { 2 - 4 } & $41-50$ & 25 & 5 \\
\cline { 2 - 4 } & $51-60$ & 17 & 1 \\
\hline Years of experience & $61>$ & 4 & 2 \\
\cline { 2 - 4 } & Less than 3 & 8 & 3 \\
\cline { 2 - 4 } & $4-7$ & 21 & 1 \\
\cline { 2 - 4 } & $8-11$ & 12 & 2 \\
\cline { 2 - 4 } & $12-15$ & 11 & 3 \\
\hline
\end{tabular}

$n=77$

The characteristics of music therapy practice are presented in Table 2 . The following is described:

- Main working environment - the most preferred examples of social care services included homes for the elderly and day care centres, whereas the most preferred educational institutions were special schools or nursery schools.

- Main client population - the most frequent special needs included intellectual disability, multiple disability, autism spectrum disorder, while the least frequent included behaviour and emotional disorders. The category of the elderly consisted of typical elderly persons as well as persons with dementia or Parkinson's disease. Other client groups included chronically sick patients and persons after stroke.

- Main music therapy methods/techniques (for example improvisation or music and movement) and the most preferred musical instruments - these items enabled respondents to apply multiple choices and, therefore, the number of answers is higher than the number of respondents. 
Table 2 Characteristics of music therapy practice

\begin{tabular}{|c|c|c|c|}
\hline & & Czech Republic & Slovakia \\
\hline \multirow{4}{*}{$\begin{array}{c}\text { Main working } \\
\text { environment }\end{array}$} & Educational & 23 & 2 \\
\hline & Social care & 30 & 10 \\
\hline & Private practice & 5 & 1 \\
\hline & Health care & 8 & 2 \\
\hline \multirow[t]{5}{*}{ Client groups } & $\begin{array}{c}\text { Persons with special } \\
\text { needs }\end{array}$ & 39 & 9 \\
\hline & $\begin{array}{l}\text { Typical children and } \\
\text { youth }\end{array}$ & 7 & 3 \\
\hline & Elderly & 8 & 1 \\
\hline & Psychiatric patients & 7 & 1 \\
\hline & Other groups & 3 & 3 \\
\hline \multirow{8}{*}{$\begin{array}{c}\text { Music therapy } \\
\text { methods/techniques }\end{array}$} & Improvisation & 59 & 12 \\
\hline & Vocal improvisation & 25 & 2 \\
\hline & Receptive techniques & 28 & 6 \\
\hline & Song-writing & 10 & 7 \\
\hline & Guided imagery & 22 & 2 \\
\hline & Singing songs & 36 & 9 \\
\hline & $\begin{array}{l}\text { Recording of clients' } \\
\text { music }\end{array}$ & 3 & 1 \\
\hline & Music and movement & 35 & 8 \\
\hline \multirow{9}{*}{$\begin{array}{l}\text { Most preferred musical } \\
\text { instruments }\end{array}$} & Piano & 29 & 6 \\
\hline & Acoustic guitar & 35 & 7 \\
\hline & Drums/Djembe & 47 & 11 \\
\hline & $\begin{array}{l}\text { Harp, lyre, kantel or } \\
\text { other similar } \\
\text { instruments }\end{array}$ & 25 & 3 \\
\hline & $\begin{array}{l}\text { Small percussions } \\
\text { (such as Orff, rumba } \\
\text { balls, rain) }\end{array}$ & 57 & 13 \\
\hline & $\begin{array}{l}\text { Flute, ending, double, } \\
\text { fujara }\end{array}$ & 32 & 6 \\
\hline & $\begin{array}{c}\text { Xylophone, } \\
\text { metallophone }\end{array}$ & 36 & 10 \\
\hline & $\begin{array}{l}\text { Patam, Handpad, } \\
\text { Handdrum, Sundrum }\end{array}$ & 20 & 5 \\
\hline & Ocean drum & 32 & 7 \\
\hline
\end{tabular}

$n=77$

\section{Research results and interpretation}

This section presents the data on respondents' experience with VMT, preferences for VMT use after the pandemic, methods of ICT use in music therapy sessions, as well as preferences for the use of ICT in future music therapy practice.

The experience of respondents with VMT gained before the pandemic is greater than expected, which confirms their effort to perform music therapy in the virtual space. However, respondents' preferences concerning VMT in the future are largely negative. This result could have been influenced by the time of data collection, because in May 2020, the Czech Republic 
was close to the end of the lockdown and most of the population did not believe in the reintroduction of preventive measures, which eventually took place in autumn 2020. At that time, a significant proportion of respondents were convinced about face-to-face music therapy, especially as there was seemingly no need to adapt to VMT as a result of the preventive measures. However, of the total number of respondents, some seriously considered the inclusion of VMT in their practice after the pandemic.

Table 3 Experience with VMT / preferences for VMT

\begin{tabular}{|c|c|c|c|}
\hline & & Czech Republic & Slovakia \\
\hline Previous experience & Yes & 15 & 2 \\
\cline { 2 - 4 } with VMT & No & 49 & 11 \\
\hline \multirow{4}{*}{$\begin{array}{c}\text { Preferences for using } \\
\text { VMT in the future } \\
\text { (Likert scale) }\end{array}$} & 1 (no preference for use) & 24 & 4 \\
\cline { 2 - 4 } & 2 & 8 & 0 \\
\cline { 2 - 4 } & 3 & 5 & 0 \\
\cline { 2 - 4 } & 4 & 4 & 0 \\
\cline { 2 - 4 } & 5 & 3 & 4 \\
\hline \multirow{2}{*}{$n=74$} & 6 & 9 & 4 \\
\hline
\end{tabular}

The remaining questions related to the use of ICT and were not directly related to VMT. Respondents also described ICT applications used in face-to-face therapeutic sessions. The responses (Table 4) suggest that more than half of respondents used ICT directly in music therapy sessions, especially during receptive activities. Specific examples of other types of ICT use included a singing book application, matching music with vibrations and light effects in Snoezelen, or simulation of musical instruments using iPad during active music therapy.

In this case, too, respondents could indicate whether they would like to use ICT in future music therapy sessions. In this case, the attitude to ICT was more balanced than in the case of VMT, with a number of respondents willing to deepen their knowledge in ICT. The biggest barriers to the use of ICT in music therapy practice as suggested by respondents included the unavailability and cost of technology, as well as education in the area of ICT. Some respondents showed their willingness to participate in courses aimed directly at music therapy in specific population groups.

Table 4 Use of ICT in music therapy

\begin{tabular}{|c|c|c|c|}
\hline & & Czech Republic & Slovakia \\
\hline \multirow{3}{*}{$\begin{array}{c}\text { Use of ICT in music } \\
\text { therapy sessions }\end{array}$} & For active music therapy & 15 & 5 \\
\cline { 2 - 4 } & For receptive music therapy & 29 & 7 \\
\cline { 2 - 4 } & Respondent does not use ICT & 30 & 3 \\
\hline Ways of using ICT & For recording and storing client data & 43 & 8 \\
\cline { 2 - 3 } & Music applications for PC & 7 & 3 \\
\cline { 2 - 3 } & $\begin{array}{c}\text { Music applications for tablet/mobile } \\
\text { phone }\end{array}$ & 19 & 4 \\
\cline { 2 - 4 } & ICT as a compensation aid in MT & 10 & 0 \\
\cline { 2 - 4 } & $\begin{array}{c}\text { Specific devices such as SoundBeam or } \\
\text { Cymis }\end{array}$ & 3 & 1 \\
\cline { 2 - 4 } & Computer controlled therapy & 1 & 0 \\
\cline { 2 - 4 } & Interactive board & 3 & 1 \\
\cline { 2 - 4 } & $\begin{array}{c}\text { Visualization (light stimuli according to } \\
\text { ICT controlled music) }\end{array}$ & 4 & \\
\hline
\end{tabular}




\begin{tabular}{|c|c|c|c|}
\hline \multirow{4}{*}{} & ICT controlled vibration stimuli & 4 & 1 \\
\cline { 2 - 4 } & Online internet/cloud services & 25 & 5 \\
\cline { 2 - 4 } & I do not use ICT & 6 & 0 \\
\hline Preferences for using & 1 (no preference for use) & 11 & 1 \\
\cline { 2 - 4 } ICT in music \\
therapy practice in \\
\cline { 2 - 4 } the future (Likert & 2 & 5 & 3 \\
\cline { 2 - 4 } scale) & 3 & 11 & 0 \\
\cline { 2 - 4 } & 4 & 8 & 3 \\
\cline { 2 - 4 } & 5 & 9 & 3 \\
\cline { 2 - 4 } & 7 (maximum preference for use) & 7 & 1 \\
\hline
\end{tabular}

$n=74$

\section{Discussion and conclusion}

On the basis of the data presented in the previous section, the answers to the research questions are as follows:

- $\quad$ Only a few music therapists have gained experienced in VMT. However, a small number of music therapists consider the use of VMT after the release of the preventive measures due to the pandemic.

- $\quad$ Music therapists use ICT primarily for receptive music therapy (listening to music) and administration. Some music therapists use internet/cloud services and music applications for client intervention.

- In the use of ICT, music therapists face barriers in the form of insufficient skills and education in the form of ICT use, as well as its cost and unavailability.

The results of the questionnaire survey suggest that Czech music therapists need to be supported in the use of ICT in their therapeutic practice and that their interest in VMT is not necessarily linked to the necessity to adapt to the virtual environment due to the preventive measures that made face-to-face contact with clients impossible. In this respect, VMT appears to be a potentially legitimate form of music therapy (Negrete, 2020). Moreover, according to World Health Organisation (2021) estimates, a rapid end to the pandemic cannot be expected and although it is not clear whether there will be more lockdowns in the following months, including strict restrictions on physical contact, the interest in VMT is likely to increase even among those music therapists who held a negative attitude during the pandemic. The majority of respondents in this study work in social services and schools that have so far been strongly affected by the preventive measures and whose therapeutic practice could again be at risk of suspension.

The greatest obstacle for therapists is the lack of knowledge and experience concerning ICT. Therefore, appropriate training activities need to be created for these purposes. The current need for the adaptation of music therapy practice to VMT should not be haphazard; without sufficient knowledge of VMT techniques and online platforms, music therapists can easily gain negative experience and thus confirm their belief that the virtual environment is not suitable for music therapy. Musical improvisation was identified by respondents as the most common method in their practice, and it is musical improvisation that brings the greatest challenges in the online space. Addressing these challenges requires the knowledge of specific adaptations (Berman, 2020; Knott \& Block, 2020). Although there is only limited scientific evidence for VMT (Kantorová et al., 2021), it is desirable to implement previously mentioned recommendations in therapy practice and ensure the highest possible quality of music therapy carried out in the virtual environment.

One of the activities that used the data from this survey is an implementation project entitled "Implementation of virtual music therapy into the private practice of Czech music 
therapists: a best practice implementation project", which started in May 2021 and the objective of which is to implement the best evidence-based practice concerning VMT into the practice of Czech music therapists, to increase the number of clients served, and to improve their satisfaction with music therapy services. In addition to supporting music therapists in using VMT, attention should also be on supporting various forms of ICT during face-to-face sessions. As far as music and music therapy technology in the Czech Republic is concerned, a relatively great focus is on vibroacoustic therapy (Vilímek, Kantor, \& Kořínková, 2021) and other vibration platforms (for example using a vibration platform). In the past, a modification of the Japanese cybernetic tool CYMIS was developed (Koucun \& Kantor, 2016).

In the interpretation of the results, the limitations of the present study must be considered, relating especially to external and internal validity. The data were obtained from a limited number of practising music therapists and, for practical reasons, the research sample was not selected in a representative manner and was based on relatively broad inclusion criteria. A nonstandardized questionnaire was used for data collection and the results cannot be compared with a control group. On the other hand, the recommendations and conclusions based on the present research would probably not change if more respondents were involved. Moreover, the research focused on a highly topical issue and the results were required for timely implementation of interventions in order to protect the Czech music therapy community (including music therapy clients) from much more serious impacts of the pandemic.

\section{Acknowledgements}

The publication of this paper was supported by the project titled "Research on inclusion of individuals with special needs", IGA_PdF_2021_024.

\section{References}

Berman, A. (2020, December 20). Music Connects Us: The Use of Music and the Role of Music Therapy during a Pandemic Crisis Situation EMTC. Retrieved from . https://www.emtceu.com/

Fuller, A. M., \& McLeod, R. G. (2019). The Connected Music Therapy Teleintervention Approach (CoMTTA) and its application to family-centred programs for young children with hearing loss. Australian Journal of Music Therapy, 30, 12-30.

Gaddy, S., Gallardo, R., McCluskey, S., Moore, L., Peuser, A., Rotert, R., Stypulkoski, C., \& LaGasse, A.B. (2020). COVID-19 and Music Therapists' Employment, Service Delivery, Perceived Stress, and Hope: A Descriptive Study. Music Therapy Perspectives. 38, 157166. https://doi.org/10.1093/mtp/miaa018

Kantor, J. et al. (2016). Společné a rozdílné v uměleckých kreativních terapiích. Palacky University Olomouc.

Kantorová, L., Kantor, J., Hořejší, B., Gilboa, A., Svobodová, Z., Lipský, M., Marečková, J., \& Klugar, M. (2021). Adaptation of Music Therapists' Practice to the Outset of the COVID-19 Pandemic - Going Virtual: A Scoping Review. International Journal of Environmental Research and Public Health, 18(10), 5138. https://doi.org/10.3390/ijerph18105138

Knott, D., \& Block, S. (2020). Virtual Music Therapy: Developing New Approaches to Service Delivery. Music Therapy Perspectives, 38(2), 151-156. https://doi.org/10.1093/mtp/miaa017

Koucun, J., \& Kantor, J. (2016). Modifications of cybernetic musical instrument CYMIS for creative rehabilitation and music education of persons with disabilities. In Proceedings 
of the 10th International Technology, Education and Development Conference. IATED. Retrieved from https://library.iated.org/view/KANTOR2016MOD

Lightstone, A.J., Bailey, S.K., \& Voros, P. (2015). Collaborative music therapy via remote video technology to reduce a veteran's symptoms of severe, chronic PTSD. Arts health, 7(2),123-136. https://doi.org/10.1080/17533015.2015.1019895

Negrete, B. (2020). Meeting the Challenges of the COVID-19 Pandemic: Virtual developmental music therapy class for infants in the neonatal intensive care unit. Pediatric Nursing, 46(4), 198.

Vaudreuil, R., Langston, D.G., Magee, W.L., Betts, D., Kass, S., \& Levy, C. (2020). Implementing music therapy through telehealth: considerations for military populations. Disability and Rehabilitation, 1-10. https://doi.org/10.1080/17483107.2020.1775312

Vilímek, Z., Kantor, J., \& Kořínková, J. (2021). The Impact of Vibroacoustic Therapy on Subjective Perception of University Students - Mixed Design Pilot Study. Universal Journal of Educational Research, 9(7), 1409-1420. https://doi.org/10.13189/ujer.2021.090707

World Health Organisation. (2021, August, 30). COVID-19 Strategic Preparedness and Response Plan. Retrieved from https://www.who.int/publications/i/item/WHO-WHE$\underline{2021.02}$ 